\title{
American Alligator Ecology and Monitoring for the Comprehensive Everglades Restoration Plan 1
}

Ken G. Rice and Frank J. Mazzotti ${ }^{2}$

\section{Introduction}

The American alligator once occupied all wetland habitats in south Florida, from sinkholes and ponds in pinelands to freshwater sloughs to mangrove estuaries. Nearly all aquatic life in the Everglades is affected by alligators (Beard, 1938). As a top predator in their ecosystem, they undergo an extraordinary change in body size and consume different prey items as they grow. As ecosystem engineers, the trails and holes that alligators build provide refuge for wading birds and fish during the dry season, and their nests provide elevated areas for nests of other reptiles and germination of plants less tolerant of flooding.

Development and water-management practices have reduced the quantity and quality of these habitats. Less freshwater moves into the mangrove zone, resulting in higher salinities and the sedimentation of creeks (Craighead, 1971). In marl prairies, the historic 6- to 9-month hydroperiod has been reduced to 3 months or less. Additionally, water levels may drop 2 feet below land surface during the dry season. Because of these habitat changes,

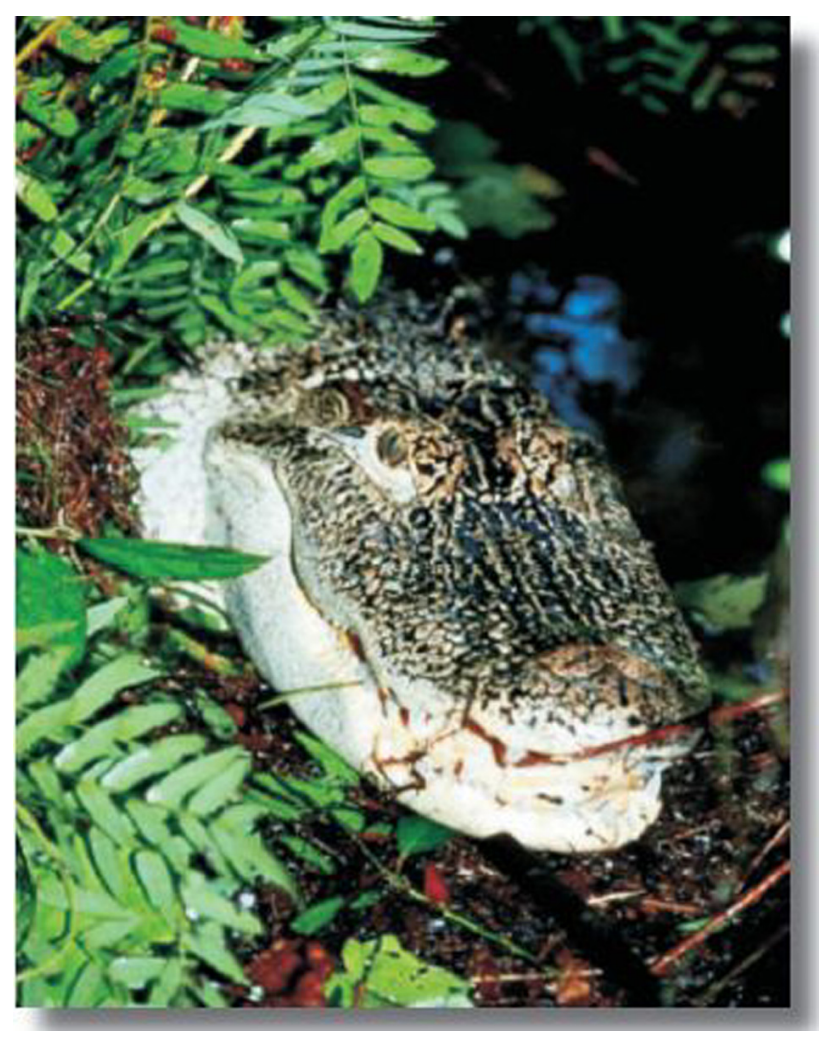

alligators are now less numerous in some habitats (Mazzotti and Brandt, 1994). As Craighead (1968) declares, "probably no phenomenon better typifies man's desecration of the southern Florida wilds than

1. This document is Cir 1478, one of a series of the Wildlife Ecology and Conservation Department, University of Florida Cooperative Extension Service, Institute of Food and Agricultural Sciences. Publication date: November, 2005. Visit the EDIS Web site at http://edis.ifas.ufl.edu. For a better understanding of figures and graphics, please print in a color printer.

2. Ken G. Rice, U.S. Geological Survey, 3205 College Ave, Davie, FL 33314, e-mail: ken_g_rice@ usgs.gov. Frank J. Mazzotti, University of Florida, 3205 College Ave, Davie, FL 33314, e-mail: fjma@ufl.edu.

The Institute of Food and Agricultural Sciences (IFAS) is an Equal Opportunity Institution authorized to provide research, educational information and other services only to individuals and institutions that function with non-discrimination with respect to race, creed, color, religion, age, disability, sex, sexual orientation, marital status, national origin, political opinions or affiliations. U.S. Department of Agriculture, Cooperative Extension Service, University of Florida, IFAS, Florida A. \& M. University Cooperative Extension Program, and Boards of County Commissioners Cooperating. Larry Arrington, Dean 
the disappearance of the alligator through his unknowledgeable attempts to manipulate nature's plan of watering the Everglades."

Currently, restoration is beginning under the Comprehensive Everglades Restoration Plan (CERP), which includes more than 68 projects ranging from removing canals to creating alternative water-storage areas. The goals of the plan include increasing spatial extent of natural areas, enhancing quality of existing natural areas, and improving abundance and diversity of native plants and animals.

An important component of the plan is an adaptive assessment process that will be used to assess the performance of CERP and recommend changes as necessary. Part of the adaptive assessment process has included the identification of key fauna and habitats that can serve as indicators of success. The American alligator was chosen due to its ties to hydrology, salinity, and system productivity, all of which should be affected during restoration.

Many important questions concerning the effects of Everglades restoration on alligator populations remain unanswered such as impacts of canal removal, the role of alligator holes as aquatic refugia, and effects of hydrology on population growth and condition. Furthermore, methods for monitoring and evaluating restoration success have not been developed across the entire Everglades system. Additionally, we need to continue to update and validate restoration tools such as population models for use in alternative selection, performance measure development, and prediction of effects of restoration. This project, a cooperative effort between the U.S. Geological Survey (USGS) and the University of Florida, will directly address the questions outlined above, develop monitoring methods, and validate restoration tools for use in CERP.

\section{Alligator Abundance}

Changes in land use and land cover resulting from water management have affected alligator populations. Some locations that were alligator habitat have been converted to agricultural and residential development. Other locations are so overdrained that alligators only occur in permanent water bodies such as canals or ponds, or during periods of extremely high water. As Everglades restoration targets restoring hydrology of these areas, re-occurrence of alligators will be an excellent indicator of success.

At present, the only long-term monitoring of alligators in Everglades National Park are aerial surveys for nests. The Florida Fish and Wildlife Conservation Commission conducts limited night surveys for alligators in and adjacent to Water Conservation Areas 2 and 3 as part of their Statewide Alligator Population Monitoring Project and aerial nest surveys as part of their Public Waters Egg Collection Program. Yet, as restoration occurs in ecosystems, such as the rocky glades and the mangrove transition zone, it will take more than 10 years for dispersing juveniles to become nesting animals. Evaluating the relative distribution, abundance, and demography of alligators allows for a more rapid and geographically balanced assessment of the impacts of CERP projects on target systems.

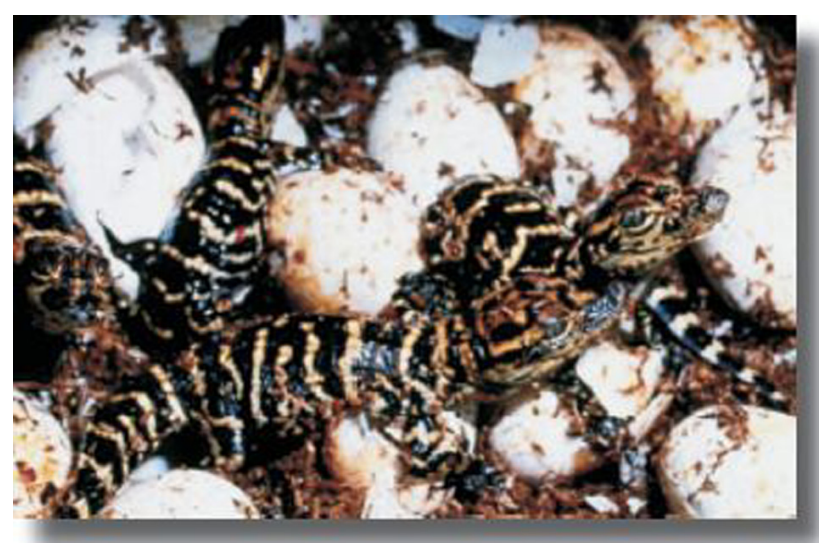

To date, survey routes have been established in estuarine rivers, freshwater canals and marshes extending from the mangrove fringe of Everglades National Park (ENP) north through Loxahatchee National Wildlife Refuge (NWR) (Fig. 1). During these surveys, we count, estimate size, and record locations of alligators on more than 300 kilometers of airboat trails, rivers, and canals in the Everglades. We conduct these surveys 4 times annually to estimate trends in populations. Currently, we are initiating research to improve our estimates of the total numbers of alligators present on the survey routes using radio-telemetry and statistical estimation techniques. To evaluate restoration success, this survey network will ultimately be able to detect change in alligator populations on the order of 5 
percent annually over a 2- to 3-year period. The alligator survey network described above is the first system-wide, systematic effort to monitor Everglades alligator populations.

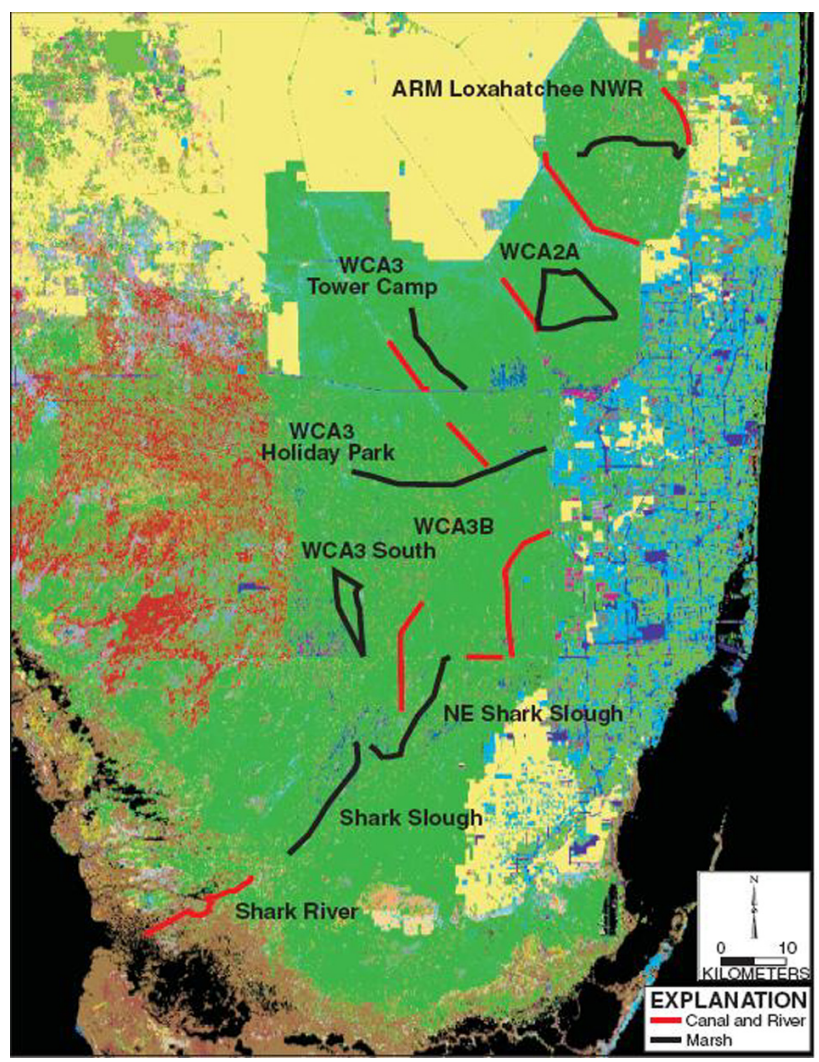

Figure 1. Alligator survey routes in the Everglades

\section{Alligator Condition}

Body condition (a relationship between body length and weight) of alligators can change over short time periods when the amount of prey available changes. In the Everglades, this is closely tied to hydrology. As water depth increases, prey become dispersed across the landscape, alligators find less prey, and body condition decreases. As water depth decreases, prey become concentrated in alligator holes, alligators capture more prey, and body condition increases. Of course, if water depth decreases too low or remains low for too long, prey become less numerous and alligator body condition suffers or cannibalism occurs, or both.

Condition has been of interest to researchers because of its ability to assess how crocodilians are coping with their environment. Measures of body condition can provide a measure of restoration success through an examination of alligators spatially and temporally in the Everglades. Condition can be viewed as a measure of the quality and accessibility of prey species and provide a linkage to lower trophic levels and their success during restoration.

Monitoring of condition in both newly restored habitats such as the rocky glades and in existing population centers is critical to an understanding of effects of restoration.

We have established monitoring sites throughout the Everglades to assess body condition and to develop relationships between hydrology and body condition. To date, we have captured more than 1,000 alligators (Fig. 2) to evaluate body condition across the Everglades. Over the first 4 years of monitoring, we have seen a decrease in all areas (Fig. 3). While this may be a short-term effect due to rainfall patterns in southern Florida, it does point out the sensitivity of the monitoring program to changes in hydrology and the usefulness of these data during restoration.

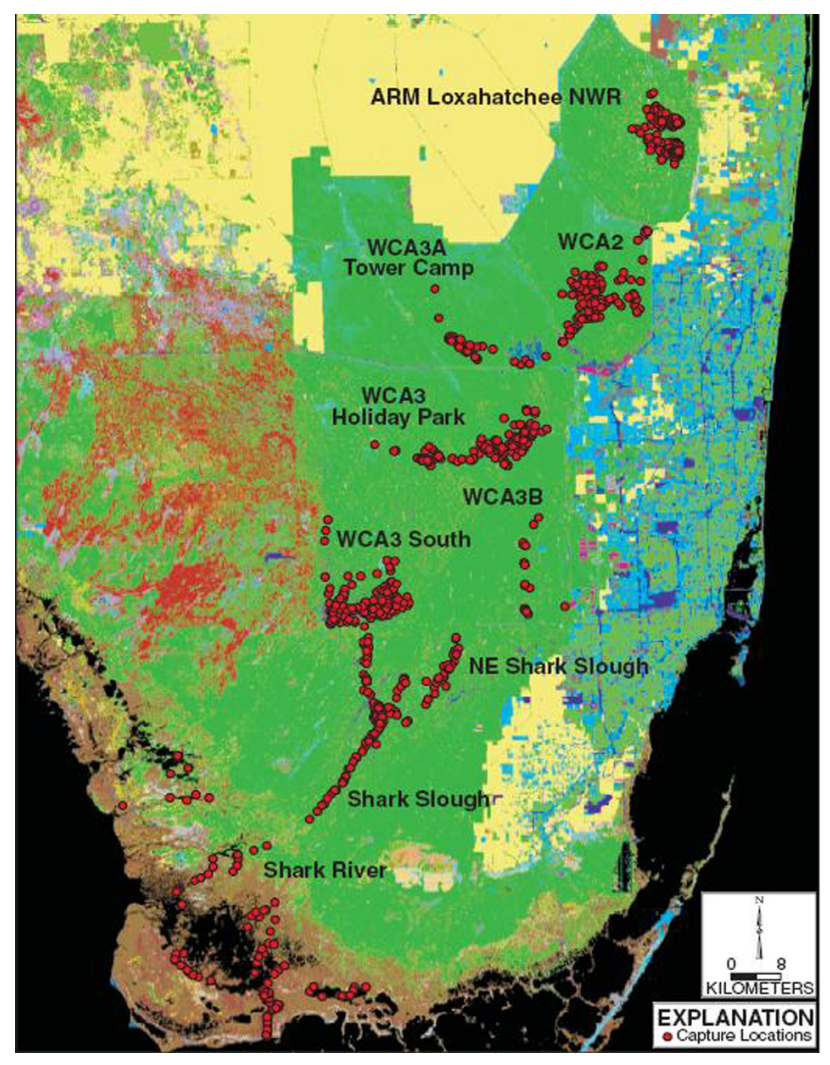

Figure 2. Location of alligators captured for assessment of body condition in the Everglades. 


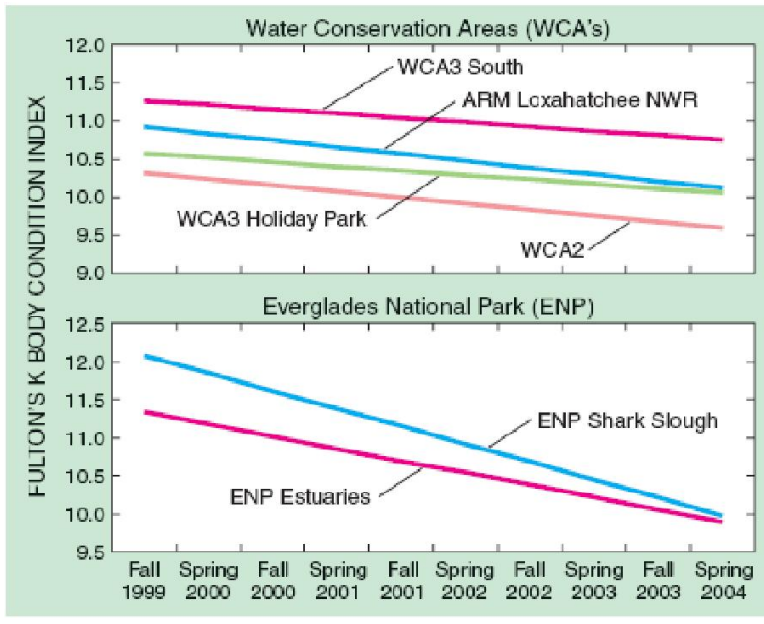

Figure 3. Alligator body condition of alligators in the Everglades from 1999 to 2004.

\section{Alligator Holes}

Alligator holes are excavated from the muck and peat that make up the Everglades soil, often down to the limestone bed. These depressions provide an aquatic refuge for alligators and other aquatic organisms, nest sites for other reptiles, and colonization sites for plants in the Everglades. Alligator holes provide foraging sites for wading birds, turtles, and snakes and also may provide refuge sites for fish during the dry season. Fish that make it through the dry season in an alligator hole are one source of future fish populations. Furthermore, alligator trails free of vegetation around gator hole sites may result in a firebreak that provides protection to woody vegetation and various animal species (Craighead, 1968).

Although alligator holes and other dry-season refugia have long been recognized as a critical component of the Everglades ecosystem, only one alligator hole until recently had been studied in detail (Kushlan, 1972). Current studies have concentrated on the ecological role and landscape pattern of alligator holes in the Everglades. While this understanding can reiterate the importance of alligator holes in the Everglades and provide linkages between species necessary for refining ecological models, monitoring density and occupancy of alligator holes is essential to the evaluation of restoration success.

Currently, we are mapping alligator holes throughout the Everglades as a baseline for ecological

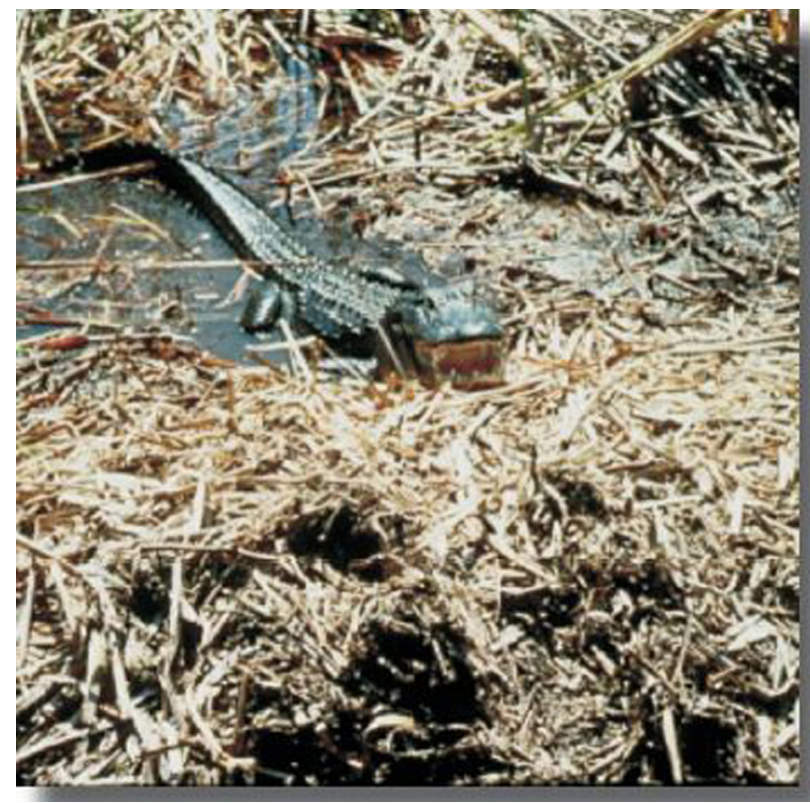

models of alligators, fish, wading birds and other species. This effort has identified several key relationships critical to restoration, including a decrease in density of alligator holes near canals (Fig. 4). Fewer alligator holes lead to fewer refuges, and feeding sites for wading birds, fish, and other reptiles as canals, for example, are too deep for wading bird foraging. Furthermore, we are developing a monitoring program to track trends in alligator hole density and occupancy. We are planning aerial transects throughout the Everglades to assess change in number, size, and types of alligator holes and the presence of alligators. Increases in number of alligator holes and alligators that maintain them would be an indication of restoration success in overdrained habitats.

\section{Alligator Models}

Predicting how restoration alternatives will influence wildlife populations and community patterns is a task that the USGS and its cooperators have undertaken in the "Across Trophic Levels System Simulation" (ATLSS) project. This large-scale, spatially explicit set of landscape models of hydrologic conditions and populations of plants and animals includes the American alligator population model (APM). By applying the APM to proposed restoration projects, current hydrologic management schedules, and historic conditions, we can examine and compare model predictions of effects on alligator population density, survival, 


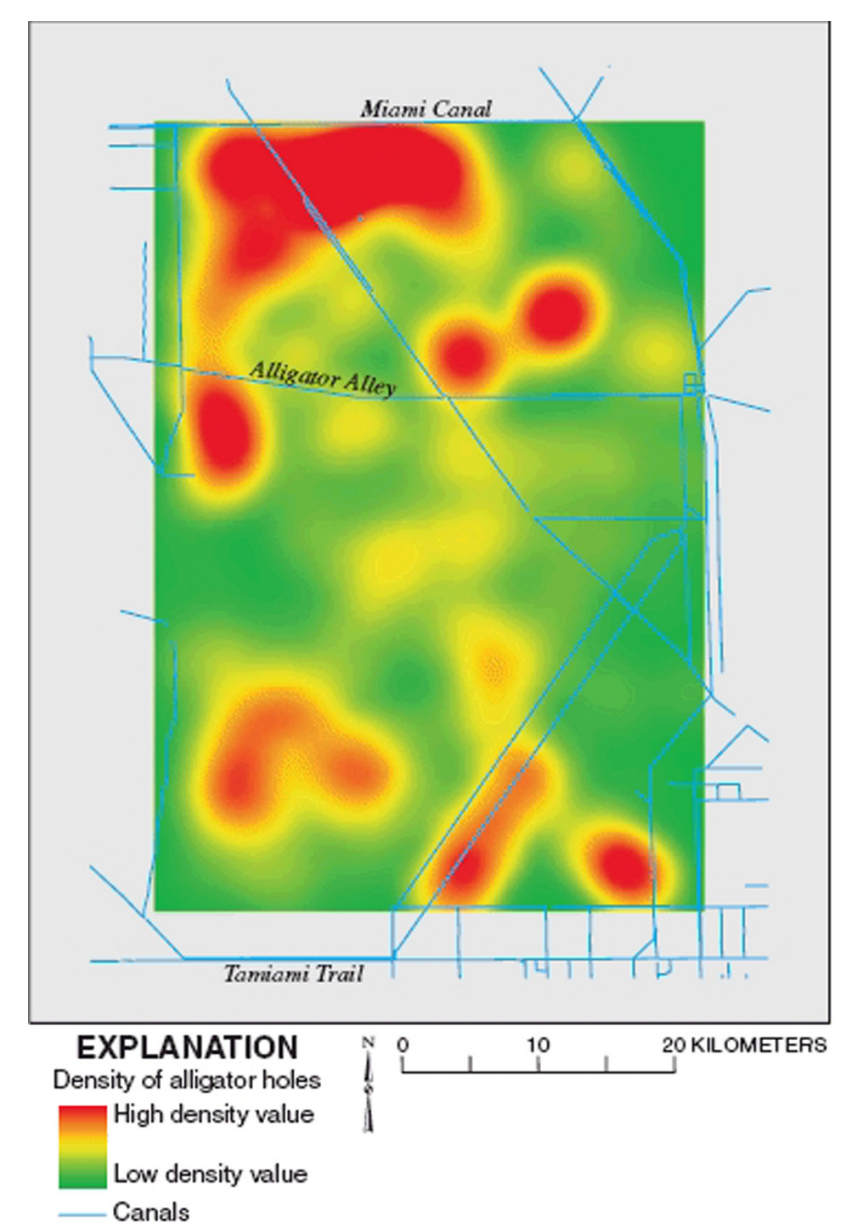

Figure 4. Alligator hole density in Water Conservation Area 3.

reproduction, and dispersal. Restoration managers can use model output to make decisions about which alternatives to implement and monitor.

Comparisons of base conditions (1995 and 2050) to the selected CERP alternative, D13R, suggest that alligator populations would increase after restoration in many of the overdrained wetlands of the Everglades (Figs. 5 and 6). However, the model predicted that some habitats, such as Shark River Slough in ENP, which is projected to have increased water depths under CERP, will either maintain populations at present levels or experience slight declines. Our results concur with predictions made by crocodilian biologists working in the Everglades.

We will continue to update and validate the model as further research results become available. For example, we have developed "virtual" night-light survey routes that correspond with our monitoring network to track how well the model predicts actual conditions. As new alternatives are proposed, the model can be used to assist managers in making informed decisions.

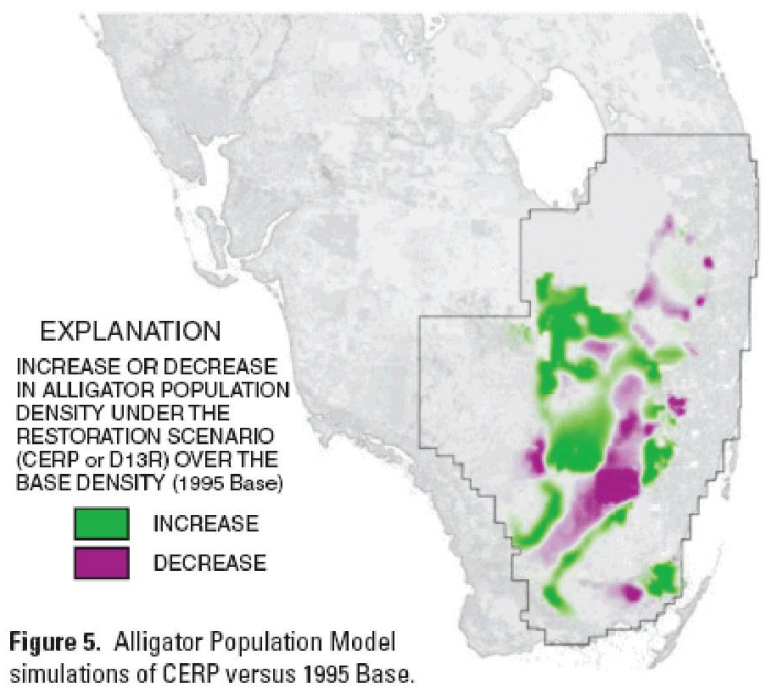

Figure 5. Alligator Population Model simulations of CERP versus 1995 Base.

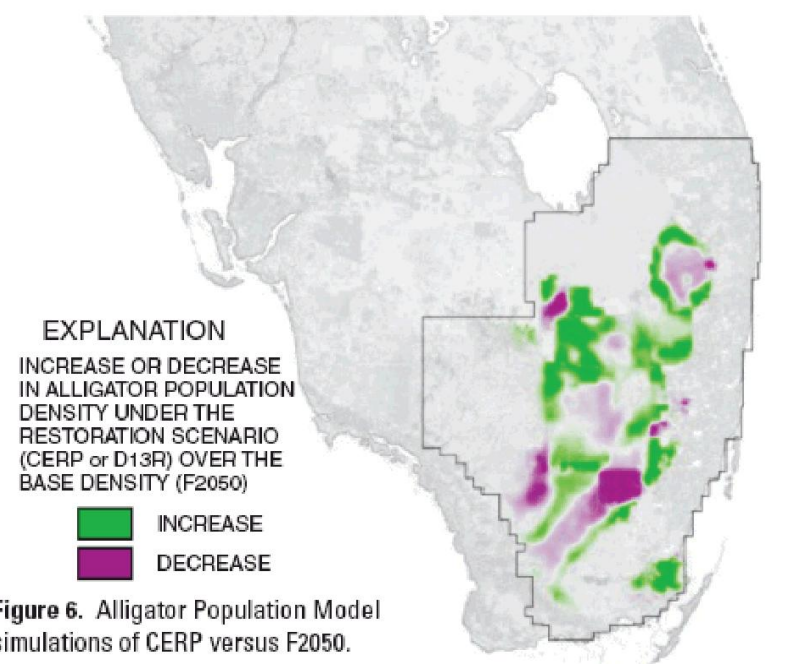

Figure 6. Alligator Population Model simulations of CERP versus F2050.

\section{Restoration Success}

During Everglades restoration, managers will require predictions about how proposed changes might affect populations of indicator species and monitoring data to ensure that success has occurred. This information will be required over short- and long-term periods and across the spatial extent of the Everglades. Our program provides a set of tools including predictive models (APM) and monitoring over short (body condition), medium (alligator 
distribution), and long (alligator hole) time periods that occur across the breadth of the Everglades system. The USGS Priority Ecosystem Science (PES) Program that supports this research has been instrumental in acquiring further funding from the U.S. Army Corps of Engineers and the CERP Monitoring and Assessment Plan to continue this research including new monitoring components such as alligator nesting.

\section{References Cited}

Beard, D.B., 1938, Everglades National Park Project: Wildlife Reconnaissance: U.S.Department of the Interior, National Park Service. Washington, D.C.

Craighead, F.C., Sr., 1968, The role of the alligator in shaping plant communities and maintaining wildlife in the Southern Everglades: Florida Naturalist, 41:2-7, p. 69-74.

Craighead, F.C., Sr., 1971, The trees of south Florida: The natural environments and their succession: Miami, Florida, University of Miami Press.

Kushlan, J.A., 1972, An ecological study of an alligator pond in the Big Cypress Swamp of southern Florida: MS Thesis, University of Miami, Coral Gables, Florida.

Mazzotti, F.J., and Brandt, L.A., 1994, Ecology of the American alligator in a seasonally fluctuating environment; in S. Davis and J. Ogden, (eds.), Everglades: The Ecosystem and its Restoration: Delray Beach, Florida, St. Lucie Press, p. 485-505. 